\title{
La ópera en la prensa peruana. Características y análisis de la información musical
}

Recibido: 11 de agosto de 2013

Aceptado: 10 de marzo de 2014

Publicado: 28 de noviembre de 2014
Pablo Macalupú Cumpén

macalupu.pablo@gmail.com

Universidad de San Martín de Porres (Perú)

Resumen: El incremento de la actividad cultural en el Perú en los últimos años requiere un complemento desde los medios de comunicación que aporte al progreso de este sector y a la formación de públicos. Además, la cultura y la educación, así como la economía, son factores clave para el desarrollo de la sociedad y los medios deben asumir su responsabilidad social no sólo emitiendo mensajes informativos, sino también instructivos, críticos y orientadores. Según especialistas y profesionales dedicados a la música académica y lírica, el periodismo cultural en el Perú no está completamente desarrollado: en muchas ocasiones se omiten eventos de gran trascendencia y en otras solo se publican aspectos triviales. En ese sentido, para abordar este tipo de temas, los profesionales de la información requieren una preparación constante y un alto sentido de la ética que los lleve a construir una sección sólida con información útil para el público.

Palabras clave: Periodismo, cultura, sociedad, periodismo cultural, prensa, noticias, crítica, ópera, música, desarrollo de la sociedad, opinión.

\begin{abstract}
The increased cultural activity in Peru within the last years requires a media complement that contributes to advance in this sector and educate the public. In addition: culture, education and economy are key factors for social development and media must assume their responsibility by not just emitting informative messages, but also instructive, critic and orientated ones. According to academic and operatic music specialists and professionals, cultural journalism in Peru is not fully developed: in many situations great importance events are omitted and in others only trivial aspects are published. In that sense, to address such issues information professionals require a constant preparation and a high sense of ethics so they build a solid section with useful information for the public.
\end{abstract}

Key words: Journalism, Culture, Society, Cultural Journalism, Media, News, Opera, Music, Social Development, Review. 


\section{Introducción}

En los últimos tiempos, muchos periodistas han debatido sobre la existencia de la especialidad cultural de la profesión en el Perú. Varios coinciden en que la tendencia actual es fomentar el periodismo cultural a través de las nuevas tecnologías, ya sea en revistas digitales, blogs, videoblogs u otros formatos de presentación a través de la web, puesto que se le da menos espacio en medios tradicionales como los periódicos ${ }^{1}$.

En referencia directa a los periódicos, los editores prefieren el periodismo de espectáculo. No obstante, el lector puede encontrar información cultural, en un reducido espacio compartido con los crucigramas, sudokus y horóscopos, en algunos medios como El Comercio, La República o El Peruano. Y si se habla de periodismo cultural sobre ópera, será más difícil de encontrar contenidos al respecto. En su defensa, podrían decir que no hay actividad lírica en el Perú, pero resultaría una afirmación falsa.

La actividad lírica en el Perú ha crecido en los últimos tiempos gracias al esfuerzo de diversas asociaciones privadas que, año a año, buscan auspicios para financiar sus producciones. A estas entidades se suma la aparición de plazas como el Gran Teatro Nacional e incluso la reinserción del Teatro Municipal de Lima al circuito cultural local. Además, contribuye el éxito internacional de personajes como el tenor Juan Diego Flórez, cuyo dominio del arte de la técnica del canto ha llamado la atención incluso de personas ajenas a la ópera, motivando que se interesen por este arte ${ }^{2}$.

Siendo entonces el periodismo una profesión dedicada permanentemente al servicio de la sociedad, resulta importante conocer más sobre su rama cultural y sobre cuáles son las características que tiene la difusión de informaciones relacionadas a la música lírica. Material que, por sus contenidos, deberían contribuir con la formación de públicos, ampliar el conocimiento y fomentar un sentido crítico en el lector respecto a la apreciación de arte.

Este trabajo presenta los resultados de una investigación sobre las características del periodismo cultural en la música lírica, centrada principalmente en el análisis de contenido de 25 noticias de la sección "Luces" de El Comercio publicadas entre el 2007 y 2011 sobre las temporadas de ópera realizadas en Lima.

1. Por ejemplo, Paola Reaño, subeditora de la revista Buensalvaje, señala que en el sector faltan políticas culturales más francas y arriesgadas. "A veces nos quedamos adormecidos por los malos augurios (el 'nadie lee' o 'aquí los artistas se mueren de hambre') y pasamos por alto que esa ausencia de plataformas culturales es también responsabilidad nuestra [...] Parte de nosotros crear estos espacios y sobre todo mantenerlos" (ápud Sánchez, 2013).

2. Molinari (2013) señala que los personajes que más han resaltado el nombre del Perú en el mundo son los cantantes líricos, poniendo como ejemplos al tenor Alejandro Granda, exitoso entre los años 1920 y 1950; a Luis Alva, cuya actividad estuvo entre los años de 1950 y 1970; Ernesto Palacio, que destacó desde la década de 1970 hasta 1998; y, finalmente, Juan Diego Flórez, que viene realizando una importante carrera internacional desde 1997. 


\section{Metodología}

El criterio para escoger noticias referidas a las temporadas líricas radica fundamentalmente en la importancia del evento como un acontecimiento cultural que involucra a públicos y productoras, que tiene amplia trascendencia nacional y, en ocasiones, internacional, como se verá más adelante. Por su parte, las fechas fueron seleccionadas debido a los cambios ocurridos en el ámbito lírico como la desaparición de la Asociación Prolírica, el ascenso de la Asociación Cultural Romanza, la creación del Festival Internacional de Ópera Alejandro Granda, la reapertura del Teatro Municipal de Lima y la construcción del Gran Teatro Nacional.

La investigación fue orientada al enfoque cuantitativo y cualitativo. La apreciación cuantitativa comprende una valoración de las características medibles o con explicación numérica para el estudio morfológico de las informaciones, mientras que la sustentación cualitativa está referida al estudio de contenido.

En resumen, esta investigación del tipo descriptiva y explicativa busca responder el fenómeno que origina determinadas características en el periodismo cultural relacionado a música lírica, y además las condiciones que se ofrecen en el medio utilizado para el presente estudio.

\section{La cultura, el periodismo y sus roles en beneficio de la sociedad}

\subsection{Aportes de la cultura al desarrollo de la sociedad}

Durante la Conferencia Mundial sobre Políticas Culturales realizada entre julio y agosto del año 1982 en México, liderada por la UNESCO (1982), la comunidad internacional firmó una declaración en la que el término cultura se definía de la siguiente manera:

"La cultura puede considerarse actualmente como el conjunto de los rasgos distintivos, espirituales y materiales, intelectuales y afectivos que caracterizan a una sociedad o un grupo social. Ella engloba, además de las artes y las letras, los modos de vida, los derechos fundamentales al ser humano, los sistemas de valores, las tradiciones y las creencias y que la cultura da al hombre la capacidad de reflexionar sobre sí mismo. Es ella la que hace de nosotros seres específicamente humanos, racionales, críticos y éticamente comprometidos. A través de ella discernimos los valores y efectuamos opciones. A través de ella el hombre se expresa, toma conciencia de sí mismo, se reconoce como un proyecto inacabado, pone en cuestión sus propias realizaciones, busca incansablemente nuevas significaciones, y crea obras que lo trascienden".

Es importante, además, detallar algunos puntos de la declaración en la que la comunidad internacional reconoce a la cultura como una "dimensión fundamental del proceso de desarrollo". Este último término es definido en el mismo número 10 de la declaración como el que "persigue el bienestar y la satisfacción constante de cada uno y todos". 
El punto 18 de esta declaración se refiere también a otro aspecto importante vinculado a cultura y sociedad: la democracia. La cultura procede de la comunidad entera y a ella debe regresar. No puede ser privilegio de élites, ni en cuanto a su producción ni en cuanto a sus beneficios. La democracia cultural supone la más amplia participación del individuo y la sociedad en el proceso de creación de bienes culturales, en la toma de decisiones que conciernen a la vida cultural y en la difusión y disfrute de la misma" (UNESCO, 1982: web).

Kliksberg (1999: web) destacó que la cultura es parte importante del capital social calificándola de instrumento formidable para el progreso económico y social; pero además de ser solo un instrumento, señala, el desarrollo cultural enriquece el espíritu de una sociedad y sus individuos. Por su parte Guédez (2002: web) escribió una serie de aportes de la cultura y la educación al capital social en aspectos de sustentabilidad, cooperatividad y gobernabilidad (figura 1):

Figura 1: Aportes de la cultura y la educación al capital social.

\begin{tabular}{|c|c|c|}
\hline DIMENSIONES & ASPECTO & APORTES DE LA CULTURA Y LA EDUCACIÓN \\
\hline \multirow{3}{*}{ Sustentabilidad } & $\begin{array}{l}\text { Crecimiento } \\
\text { económico }\end{array}$ & $\begin{array}{l}\text { La cultura y la educación potencian la conciencia productiva y } \\
\text { fomentan una motivación hacia el logro. }\end{array}$ \\
\hline & Equilibrio social & $\begin{array}{l}\text { La cultura y la educación crean conciencia social y sentido de } \\
\text { responsabilidad comunitaria. }\end{array}$ \\
\hline & $\begin{array}{l}\text { Preservación } \\
\text { ambiental }\end{array}$ & $\begin{array}{l}\text { La cultura y la educación promueven las sensibilidades } \\
\text { requeridas para el cultivo y preservación ambiental. }\end{array}$ \\
\hline \multirow{3}{*}{ Gobernabilidad } & Institucionalidad & $\begin{array}{l}\text { La cultura y la educación generan conciencia institucional y } \\
\text { espíritu de institucionalización. }\end{array}$ \\
\hline & Conciencia cívica & $\begin{array}{l}\text { La cultura y la educación fomentan creencias y conductas } \\
\text { inscritas en la convivencia social y en el respeto a las leyes que } \\
\text { rigen la vida en sociedad. }\end{array}$ \\
\hline & Confianza & $\begin{array}{l}\text { La cultura y la educación incentivan las capacidades de } \\
\text { interacción, negociación y comprensión necesarias para } \\
\text { establecer un clima de confianza. }\end{array}$ \\
\hline \multirow{3}{*}{ Cooperatividad } & Estado & $\begin{array}{l}\text { La cultura y la educación permiten orientar los esfuerzos hacia } \\
\text { los intereses comunes. }\end{array}$ \\
\hline & Empresa & $\begin{array}{l}\text { La cultura y la educación son el fundamento de las } \\
\text { competencias (informaciones, habilidades, destrezas, actitudes } \\
\text { y valores) asociados a los negocios de una empresa. }\end{array}$ \\
\hline & $\begin{array}{l}\text { Organizaciones no } \\
\text { gubernamentales }\end{array}$ & $\begin{array}{l}\text { La cultura y la educación existen en el origen, la naturaleza y el } \\
\text { propósito de las organizaciones sin fines de lucro. }\end{array}$ \\
\hline
\end{tabular}

Fuente: Guédez (2002: web). 
En suma, la cultura es un factor fundamental para el desarrollo de las sociedades, por tanto debe democratizarse y llegar a los distintos niveles socioeconómicos. Parte de la responsabilidad de hacer accesible la cultura viene también de los medios de comunicación, que deben incluir en su oferta no solo "lo que le gusta a la gente" (Gargurevich, 2009: web), sino también cumplir con una función formativa.

\subsection{El periodismo como constructor de la realidad social}

Para Contreras (2005: web), los medios construyen la realidad social por el simple hecho de darle más importancia a unos eventos y convertirlos en mediáticos o en lo que se conoce como lo actual. Por tanto, descarta las ideas utilizadas por muchos comunicadores de que los medios son meros "espejos de la realidad" y que los periodistas solo "constatan y relatan" los hechos. Además, el mencionado autor señala que la actividad periodística es principalmente interpretativa:

"La noticia no es algo tangible que está ahí esperando: existe
porque los periodistas aplican determinados procedimientos para
observar, interpretar y representar cosas que pasan en la sociedad.
No hay nada en la realidad que 'obligue' a los profesionales de la
información a colocarlo en la primera página de un periódico. Si
ofrecen una determinada noticia es porque consideran que tal hecho,
en las concretas circunstancias de tal ciudad o país, puede interesar
a un público amplio. [...] La autoridad moral del periodista y del
medio se fragua en ese saber interpretar la realidad desde dentro
y en conseguir mantener la confianza del público, mostrando que
sus valoraciones son fruto de un ejercicio profesional honesto:
que cuando decide dar o no dar una información, ofrecerla con
un relieve mayor o menor, desde un punto de vista o desde otro,
o usando determinadas expresiones, lo que se mueve son criterios
profesionales" (ibídem).

Al respecto, Martín Serrano (1984: web) explica que por un lado son los medios los que escogen los temas a presentar, así como el tiempo o espacio que se le dedicará a cada uno; y por otro lado, cada persona tendrá acceso a determinado medio "y no siempre dispone del tiempo o del horario adecuado para optar entre los distintos contenidos que un medio impreso ofrece en sus páginas, o que un medio-audio programa a lo largo de la jornada". Sobre la base de una investigación realizada al público español, el investigador señala, en el texto citado, que los medios prefieren los temas de poca relevancia como temas de "vida social", "sucesos", "frivolidades" para alienar "la participación en los problemas sociales y políticos que le afectan y en la que las audiencias poseen poca conciencia de sus problemas e intereses".

Gargurevich (2009: web) advierte que el periodismo "no es ya otra cosa que la recolección y publicación preferente de noticias de la farándula, los delincuentes y los deportistas. Quedan excluidas las informaciones políticas, económicas, culturales que ocupan espacios que pueden ser muy bien destinados a más noticias sobre farándula, delincuentes y 
deportistas". Aunque señala que hay "excepciones honrosas", la mayoría de medios usan "los mismos criterios de noticiabilidad y en consecuencia no hay ya referente, no hay manera de comparar cuál es mejor o peor" y resulta una "formidable demostración de que estamos [...] en la ruta de 'lo que le gusta a la gente"'.

Teniendo en cuenta, entonces, que los responsables de los medios son quienes definen sus propias agendas y la tendencia actual es preferir lo superficial a lo cultural o a los problemas de fondo, muchos personajes locales vinculados a este campo han debatido en el país sobre las razones por las que se dedica un espacio diminuto a la cultura. Por un lado, Fernando Ampuero afirmó que esto es generado por desinterés de los propios medios que, a lo mucho, dedican un pequeño espacio a la crítica cinematográfica y, en el peor de los casos, solo a evaluar películas con estrellas. Las otras actividades, entonces, son un "desierto de escalofrío" (ápud Sánchez, 2013: web). Por otro lado, Gumersindo Lafuente expresó que en estos tiempos "se está mezclando todo y se nos está vendiendo por cultura cosas que están más relacionadas con el espectáculo y el mercado”. En ese sentido, los medios optan por "lo que vende frente a lo interesante pero que vende menos" (ápud Yáñez, 2012: web).

Para Lafuente el periodismo cultural tiene "un campo de acción muy extenso" que debe cumplir a cabalidad con las audiencias: "hoy más que nunca las audiencias piden criterio, personas con conocimiento que les ayuden a filtrar, a decidir, a comprender. Y en los ámbitos culturales, el criterio especializado es en el que tiene más relevancia" (ibídem). Además, dicho autor se refiere a la labor periodística de investigación, la cual está más dedicada a los escándalos políticos o económicos; no obstante, considera que también podría aplicarse en el campo cultural para tratar temas "relacionados con la falsificación, con la copia, con la reproducción ilegal". La realidad es distinta, pues el periodismo cultural, en sus propias palabras, "ha tenido tradicionalmente un tono más amable" (ibídem).

\subsection{La ética en el periodismo cultural}

Otro aspecto que no debe dejarse de lado es la ética en la especialidad cultural. Para Fernando Garavito (Martín-Barbero, Ulanovsky y Garavito, 1991: 48) hay grandes retos que consisten en “indagar, romper, estigmatizar, denunciar". En ese sentido, el periodismo cultural va más allá de presentar notas con lo superficial de algún evento artístico. El profesional de esta especialidad debería manejar temas de políticas culturales, sociedad, arte en general y difundir su información con la conciencia de que su labor está al servicio del público y no de sí mismo.

Al respecto, Núñez Grassals (2011: web) planteó una pregunta que lleva a la reflexión: ¿Para quién trabaja el periodista?

"Esta sencilla pregunta... abre por lo menos tres posibilidades de respuesta al parecer igualmente sencillas, pero en esencia de grados distintos de problematización $\mathrm{y}$, por tanto, de utilidad y alcances también distintos a la luz del criterio ético:

a) El periodista trabaja para sí mismo. 
b) El periodista trabaja para la empresa de prensa.

c) El periodista trabaja para la sociedad.

Cada una de esas respuestas conduce al despliegue de un programa ético diferente, tiene costos diferentes y da lugar a efectos también diferentes. En fin: el acto ético no es gratuito. Tiene consecuencias: cuesta".

Tratar la ética en el periodismo cultural es también tratar un género de opinión recurrente en este campo como es la crítica, que requiere un alto sentido ético de parte de quien la firme. Natividad Abril precisa que quien se dedique a escribir crítica debe cumplir con dos condiciones: "gustarle la especialidad artística que elija y un elevado concepto de la honestidad" (ápud Yanes, 2005: web). Además, señala que es necesario evitar los prejuicios razón por la cual se debe formar una opinión basada en un análisis riguroso de la obra. En ese sentido, Rivas Iturralde (2010: web) detalla:

"Un comentario crítico bien escrito logrará transmitir al lector la emoción provocada por la música en el crítico. Y esa emoción no suele provenir de un encendido lirismo estilístico como de una gran exactitud en las palabras. Las de Alfred Einstein, por ejemplo, acerca del Quinteto en Sol menor K. 516 de Mozart, poseen una emoción contagiosa. Por otra parte, una descripción puramente adjetivada de una obra musical será superficial e insuficiente, pura palabrería, si no se sustenta en el descubrimiento y reflexión de los hallazgos técnicos".

\section{La lírica en el Perú en los últimos treinta años}

Si bien el Perú ha sido un país de intensa actividad lírica, esta no se ha cultivado adecuadamente debido a una ausencia de políticas culturales que garanticen estabilidad y constante movimiento del sector ${ }^{3}$, así como el fortalecimiento de la enseñanza musical en el país ${ }^{4}$. A ello hay que sumarle los períodos de crisis como la guerra con Chile o la dictadura militar de la década del 70 que paralizó al sector operístico 5 .

3. Molinari (2013) precisa que a inicios de la República, la actividad lírica era casi diaria con compañías como la de la soprano Rosa Merino. Del mismo modo, el compositor Juan Sixto Prieto dejó plasmado en su libro El Perú en la música escénica una larga lista de obras inspiradas en el Perú que, muchas de ellas, fueron estrenadas aquí. Su investigación va desde 1658 en adelante. Por otro lado, el musicólogo argentino Rodolfo Barbacci compuso Apuntes para un diccionario biográfico musical peruano, 96 páginas de información sobre los personajes nacionales vinculados a la actividad musical en el país.

4. Por ejemplo, es recién en el 2008, después de 100 años de creación, que el Conservatorio Nacional de Música obtiene de parte del Gobierno el reconocimiento de que los estudios superiores realizados ahí sean equivalentes a los cursados en universidades (grado académico y título profesional de licenciado).

5. Ernesto Palacio, director artístico del Festival Internacional de Ópera Alejandro Granda y agente de Juan Diego 
A partir de la década del ochenta, sin embargo, se experimentó un resurgimiento con temporadas anuales que fueron promovidas por el tenor Luis Alva. La Fundación Pro Arte Lírico (FUPAL), que años después cambió su nombre a Prolírica, presentaba tanto óperas como zarzuelas y conciertos en la ciudad, enriqueciendo la oferta cultural en ese sector ( $c f$. Asociación Cultural Romanza, 2012: web).

En cada temporada reunía a artistas extranjeros como Marco Armiliato, Roberto Servile, Svetla Krasteva, Daniela Barcellona, Stefano Pellegrino e incluso, gracias a la asociación de Alva, llegaron a Lima personajes como Teresa Berganza, Victoria de los Ángeles y Luciano Pavarotti. Además de ellos, en las temporadas de FUPAL y Prolírica también participaron artistas como Ernesto Palacio, Raúl Cragg, Claudia Clarich, María Eloísa Aguirre, Humberto Zavalaga, Francisco Petrozzi, Jacqueline Terry, Jimena Llanos, Josefina Brivio, Andrés Veramendi, Xavier Fernández, entre otros.

Según la publicación del website de la Asociación Romanza, hubo también otras entidades que aparecieron en la década de 1990 y desaparecieron en los primeros años del 2000 como Renacimiento y la Orquesta Filarmónica de Lima.

En 2001 aparecieron los Amigos Peruanos de la Ópera con la dirección artística del retirado tenor Ernesto Palacio, quien además es agente artístico de Juan Diego Flórez y otras grandes figuras mundiales de la lírica. Esta asociación presentó tanto a Flórez como a otras estrellas: Mariella Devia, Katia Ricciarelli, Paolo Bordogna, Riccardo Frizza, entre otros.

A partir del 2006, la Asociación Cultural Romanza inició oficialmente sus actividades presentando ópera y zarzuela. Para sus temporadas llegan destacados artistas internacionales como Enrique Ricci, Giuseppe Altomare, Verónica Villarroel, Emmanuel Siffert, Matteo Pagliari; además de apostar por el talento nacional con representantes como Andrés Veramendi, Josefina Brivio, Jimena Llanos, Xavier Fernández, Ximena Agurto, Rudi Fernández, entre otros. Romanza continúa vigente gracias al esfuerzo de su presidente, Enrique Bernales, y los miembros asociados que buscan auspicios para financiar las temporadas anuales.

El 2008 fue un año particularmente interesante. Además de su temporada habitual, la Asociación Romanza hizo una coproducción con los Amigos Peruanos de la Ópera y, con apoyo del Gobierno Regional del Callao, realizaron la I edición del Festival Internacional de Ópera Alejandro Granda (conocido también como Festival Granda). El programa de ese año fue Rigoletto de Giuseppe Verdi y atrajo la atención de todo el mundo ya que Juan Diego Flórez hacía su debut internacional en el personaje del Duca di Mantova.

Flórez, califica de "oscurantismo total" el período de dictadura de Juan Velasco Alvarado. Señala que hasta la década del 60 la compañía de ópera que venía normalmente presentaba varias obras en una temporada; además fue una buena época para la Orquesta Sinfónica Nacional con un director de nivel como Luis Herrera de la Fuente. De otro lado, a modo de recuerdo, el presidente de la Sociedad Filarmónica de Lima, Salomón Lerner Febres, señaló también que en la década del 60 el Teatro Municipal de Lima "funcionaba maravillosamente" y hasta pudo ver en su época de estudiante alguna función del compositor Igor Stravinski y del pianista Wilhelm Kempff. 
De otro lado, en ese mismo año Prolírica bajaba el telón tras 30 años de trabajo intenso. La asociación de Luis Alva se despidió de los escenarios con Madama Butterfly y una gala en honor a Giacomo Puccini.

En 2009, otro evento importante fue el debut mundial de Ildar Abdrazakov como Attila, en la ópera homónima de Giuseppe Verdi, que se realizó en el II Festival Granda. En 2010, los directivos deciden independizarse y continuar con el apoyo del Gobierno Regional del Callao ${ }^{6}$. Para la III edición se programó las óperas Norma, de Vincenzo Bellini y La Favorite, de Gaetano Donizetti. Este evento operístico vigente y tiene programado para su VIII edición, en el año 2015, la presentación de la ópera Lucia di Lammermoor, con la destacada soprano australiana Jessica Pratt como protagonista.

Tras su inauguración oficial en 2012, el Gran Teatro Nacional ha presentado varias producciones de ópera con una breve temporada anual, en la que reúne a los elencos nacionales (Orquesta Sinfónica Nacional, Coro Nacional del Perú, Coro Nacional de Niños y Ballet Nacional).

Esta constante actividad operística anual de diversas entidades, que incluyen producciones independientes o presentaciones de instituciones educativas (por ejemplo Idomeneo, de Mozart presentado en 2012 por la Universidad de San Martín de Porres), los medios han comenzado a prestar especial atención a las agendas y actividades que realizan los artistas nacionales en el extranjero.

Además de Juan Diego Flórez, el Perú tiene otros representantes que destacan en el mundo como los directores de orquesta Miguel Harth-Bedoya, Carmen Moral o David del Pino; cantantes líricos como Andrés Veramendi, Jimena Llanos, Josefina Brivio y Francisco Petrozzi; compositores como Jimmy López, quien recibió un encargo de la Ópera Lírica de Chicago para componer la ópera Bel Canto, una obra que se estrenará el 2015 y tratará sobre la toma de rehenes en la residencia del ex embajador japonés en el Perú sucedida entre finales de 1996 y 1997.

\section{Características del periodismo cultural peruano sobre ópera}

De acuerdo con Molinari (2013), en el Perú el periodismo cultural sobre lírica es muy superficial o mundano, ya que se queda en lo pomposo o en la anécdota y no aborda los temas de fondo. El director ejecutivo de "Sinfonía por el Perú" recuerda a Raygada como uno de los más grandes críticos que tuvo el país, función que cumplió años después Alejandro Yori y recientemente José Quezada Machiavello, hasta que terminó su colaboración con El Comercio.

\footnotetext{
6. Al respecto, Ernesto Palacio comentó: "El Festival Alejandro Granda crece y se ha vuelto adulto. Se ha independizado de las dos asociaciones que lo habían creado: Romanza y Amigos Peruanos de la Ópera". Por su parte, Aurelio Loret de Mola, quien fue presidente de la directiva, expresó: "Somos enemigos de la chapucería y de la mediocridad, presentamos óperas al nivel de los mejores teatros del mundo" (ápud Planas, 2010).
} 
Con la finalidad de analizar el periodismo cultural, centrada temáticamente en la ópera, se han revisado ediciones de $\mathrm{El} \mathrm{Comercio}{ }^{7}$. Al revisarse el material hemerográfico, se observa que la actividad lírica en el Perú ha ido creciendo poco a poco en los últimos años. Sin embargo, el espacio dedicado en El Comercio a la ópera en el país ha sido, usualmente, breve (figura 2). A continuación se detallan los resultados ${ }^{8}$ más saltantes:

Figura 2: Análisis observacional y situacional de la sección de referencia.

Cobertura informativa total.

\begin{tabular}{|c|c|c|c|c|c|c|c|c|c|c|c|c|c|c|c|c|c|}
\hline \multirow{2}{*}{$\begin{array}{l}\frac{0}{\alpha^{2}} \\
\frac{\alpha}{\bar{\alpha}}\end{array}$} & \multicolumn{10}{|c|}{ ANO / SUPERFICIE REDACCIONAL / TAMANO } & \multicolumn{3}{|c|}{$\begin{array}{l}\text { GENEROS } \\
\text { PERIODISTICOS } \\
\end{array}$} & \multirow[b]{2}{*}{ S.R. } & \multirow[b]{2}{*}{ I.P. } & \multirow{2}{*}{$\begin{array}{l}\text { IMAG. } \\
\text { FOT. }\end{array}$} & \multirow{2}{*}{ 홍 } \\
\hline & 2007 & $\begin{array}{c}\text { S.R. } \\
\mathrm{cm} / \mathrm{col}\end{array}$ & 2008 & $\begin{array}{c}\text { S.R. } \\
\mathrm{cm} / \mathrm{col}\end{array}$ & 2009 & $\begin{array}{l}\text { S.R. } \\
\mathrm{cm} / \mathrm{col}\end{array}$ & 2010 & $\begin{array}{l}\text { S.R. } \\
\text { cm/col }\end{array}$ & 2011 & $\begin{array}{l}\text { S.R. } \\
\text { cmicol }\end{array}$ & $\begin{array}{l}\text { INF. } \\
\text { NOT. }\end{array}$ & $\begin{array}{l}\text { REP. } \\
\text { INTER. }\end{array}$ & OPIN. & & & & \\
\hline \multirow{5}{*}{ 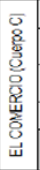 } & $4 / 08$ & $2103 \%$ & $31 / 03$ & $16.46 \%$ & $14 / 02$ & $24.20 \%$ & $5 / 01$ & $25.08 \%$ & $24 / 02$ & $37.37 \%$ & \multirow{5}{*}{17} & \multirow{5}{*}{1} & \multirow{5}{*}{7} & \multirow{5}{*}{$544.11 \%$} & \multirow{5}{*}{25} & \multirow{5}{*}{41} & \multirow{5}{*}{41} \\
\hline & $4 / 08$ & $45.68 \%$ & $2 / 04$ & $32.54 \%$ & $18 / 04$ & $12.82 \%$ & $27 / 04$ & $16.89 \%$ & $24 / 02$ & $31.09 \%$ & & & & & & & \\
\hline & $9 / 09$ & $18.34 \%$ & $28 / 07$ & $23.14 \%$ & $27 / 04$ & $13.60 \%$ & $5 / 08$ & $20.90 \%$ & $18 / 04$ & $14.31 \%$ & & & & & & & \\
\hline & $7 / 10$ & $15.61 \%$ & $2 / 11$ & $36.53 \%$ & $10 / 06$ & $12.20 \%$ & $5 / 08$ & $1923 \%$ & $22 / 05$ & $16.42 \%$ & & & & & & & \\
\hline & $21 / 10$ & $1693 \%$ & $9 / 11$ & $13.72 \%$ & $29 / 07$ & $21.60 \%$ & $30 / 08$ & $19.91 \%$ & $13 / 08$ & $18.51 \%$ & & & & & & & \\
\hline 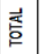 & 5 & $117.59 \%$ & 5 & $122.39 \%$ & 5 & $84.42 \%$ & 5 & $102.01 \%$ & 5 & $1177 \%$ & 17 & 1 & 7 & $544.11 \%$ & 25 & 41 & 41 \\
\hline
\end{tabular}

Fuente: Elaboración propia.

El espacio más pequeño dedicado a una noticia sobre ópera ha sido el $12.20 \%$ de la página total $(52.50$ x $29.5 \mathrm{~cm}$.), bajo el título "Temporada Lírica 2009 en el Teatro Segura" (10/ VI/2009, "Luces", p. 8). El texto no está firmado y tiene grandes similitudes con la nota de prensa enviada por la Asociación Romanza, que también habría sido copiada por otros medios ( $c f$. RPP, 2009). En el texto se encuentran varias imprecisiones en los nombres de los cantantes ("Elena Kancheva", "Jaqueline Terry", "Karoly Shnerredy"; en lugar de Ina Kancheva, Jacqueline Terry y Károly Szemerédy), y además no profundiza o detalla, por ejemplo, la importancia de las obras a presentar o la trayectoria de los cantantes.

La noticia a la que se le dedica mayor espacio en cuanto a superficie redaccional es el texto "La zarzuela despide la temporada lírica" (9/IX/2007, "Luces", p. 17), referido a la temporada lírica organizada por la Asociación Romanza, con un total de $45.68 \%$ de la página total. Este texto destaca la importancia de la presencia de artistas internacionales y también aborda, aunque en menor detalle, el programa de zarzuela. El texto no lleva firma y no cuenta con declaraciones.

7. Se procedió con la revisión de ejemplares del diario El Comercio aparecidos entre septiembre de 2007 y agosto de 2011, escogiéndose 25 noticias sobre las temporadas líricas nacionales, todas ellas aparecidas en la sección "Luces". Para el análisis de contenido se utilizaron criterios de evaluación como el medio, los géneros periodísticos, el vínculo de la noticia con otras, el tamaño del texto, la ubicación, acompañamiento gráfico, autor, los elementos del texto, los tecnicismos y la explicación del hecho.

8. Leyendas que aparecen en la tabla: S. R. cm/col. = superficie redaccional en centímetros/columna; Rep. Inter. = reportajes interpretativos; I. P. = Informaciones periodísticas; Opin. = Opinión; Inf. not. = Informaciones, noticias; Fot. $=$ Fotografía. Las celdas sombreadas corresponden a los textos de opinión. 
Una característica de la sección "Luces" de El Comercio es el predominio de la imagen sobre el contenido. En ese sentido, un hecho de importancia internacional como el debut de Juan Diego Flórez en el rol del Duque de Mantua, de Rigoletto, en el I Festival Internacional de Ópera Alejandro Granda, solo tuvo $16.46 \%$ de texto y el resto fue una fotografía de gran tamaño (figura 3)

Figura 3: Nota sobre evento musical en el diario El Comercio.

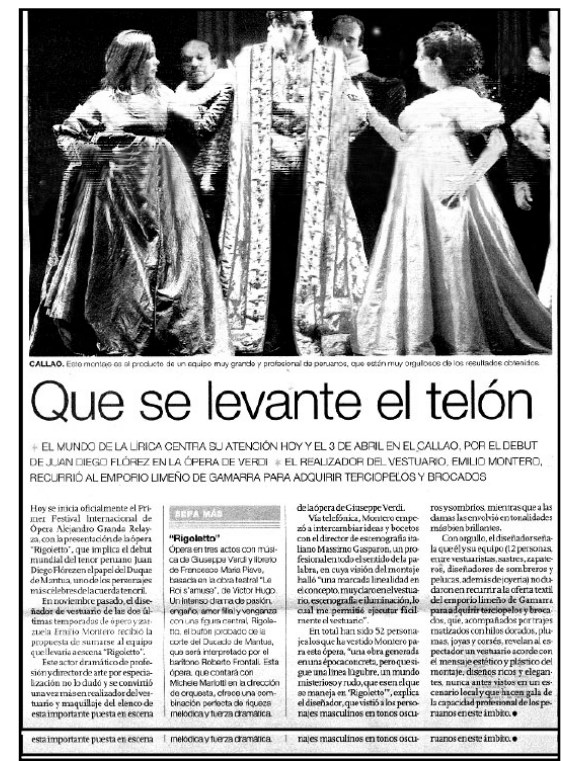

Fuente: El Comercio (31/III/2008, “Luces”, p. 4).

Precisamente este debut sí tuvo una crítica extensa firmada por José Quezada Macchiavello (2008), la cual ocupó el $32.54 \%$ del tamaño total de la página. La primera parte del texto estuvo dedicada a la importancia de la ópera para los inmigrantes italianos en el Callao; luego, el autor escribió brevemente sobre Alejandro Granda y el teatro que lleva el nombre del tenor. A continuación, se dedicó varias líneas al debut de Juan Diego Flórez y finalizó con breves comentarios del resto del elenco y la dirección orquestal y escénica.

El 28 de julio del 2008 se publicó una nota informativa sin firma sobre la temporada lírica de la Asociación Romanza en el Teatro Segura, titulada "Nueva temporada lírica en el Teatro Segura" (28/VII/2008, "Luces", p. 3). En ella se pueden observar algunas imprecisiones, como la hallada en su segundo párrafo: "La temporada inicia con las zarzuelas La Dolorosa, de José Serrano; y Antología madrileña de Federico Chueca, esta última preparada especialmente en memoria del centenario del fallecimiento del afamado compositor valenciano, considerado uno de los máximos representantes del 'género chico"”.

Según el texto, el lector podría entender que Chueca es el "afamado compositor valenciano", pero una pista para entender lo que se quiso decir está en la frase anterior 
("en memoria del centenario del fallecimiento"). El compositor Federico Chueca nació en Madrid (no es natural de Valencia) y murió en 1908. José Serrano, por su parte, sí es valenciano y murió en 1941.

Otro detalle que llama la atención es que en el penúltimo párrafo se afirma que en Tosca "los barítonos Giuseppe Altomare (Italia) y Homero Pérez-Miranda (Chile) alternarán en el rol de Piero". Como se sabe, la ópera Tosca de Puccini no tiene ningún personaje con ese nombre. El papel para barítono es Scarpia. Un error similar aparece en otro texto (Bedoya, 2010). Si bien cuenta con información importante y recoge declaraciones de la mezzosoprano Daniela Barcellona y el tenor Dmitry Korchak, se confunde el nombre del personaje Fernando y se le llama "Francisco". Se podría suponer que fue un error que pasó los filtros hasta llegar finalmente a la imprenta.

Al año siguiente, en 2009, la II edición del Festival Granda trajo otro importante debut mundial: el del bajo ruso Ildar Abdrazakov. Él estrenó en escena (ya lo había hecho antes en concierto) el rol protagónico de la ópera Attila. El diario El Comercio le dedicó dos textos que sumados no llegaron al total de espacio dedicado el año anterior a Rigoletto. El primero tuvo como encabezado "Crítica de ópera", de Alberto Servat (2009), donde dice literalmente: "dejando la evaluación musical para los entendidos". Es decir, el autor dedica su opinión exclusivamente a la producción escénica.

Como complemento al texto incompleto divulgado días atrás, se publica una columna de opinión titulada "Un elenco de clase mundial", firmada por Quezada Macchiavello (2009). En ella, el especialista detalla los aspectos musicales de la función, pero omite los escénicos (se presume que porque ya se había publicado una crítica anterior al respecto).

En febrero de 2011, El Comercio publicó una crónica a Juan Diego Flórez (Trivelli, 2011a y 2011b), como la continuación de una breve introducción informativa difundida en la portada de esa sección (destaca, como es habitual, una gran fotografía). "Andanzas de un tenor en Bogotá" (Trivelli, 2011b) abarca el 31.09\% del total de la página utilizado solo texto, mientras que el resto se completa con cuatro fotografías. El contenido es interesante, amigable para el lector y relata los proyectos del tenor con el Sistema de Orquestas Infantiles y Juveniles, así como el personaje que preparaba para presentar en Lima meses después.

Sobre este último punto, la IV edición del Festival Internacional de Ópera Alejandro Granda presentó ese año el Réquiem, de Giuseppe Verdi; y El Barbero de Sevilla, de Gioacchino Rossini. La nota titulada "Un canto para el descanso eterno" (18/IV/2011, "Luces", p. 2) presentó un contenido bastante ilustrativo sobre el Réquiem, desde sus orígenes hasta los requerimientos musicales para su realización. El texto ocupó $14.31 \%$ del total de la página e incluyó 5 fotografías, cuatro de los solistas de la obra, en tamaño pequeño; y una de Juan Diego Flórez que resaltaba mucho más que las otras, pese a que el tenor no participaba en esa obra, aunque sí era parte del Festival.

Los detalles aquí mostrados evidencian que el espacio en superficie de redacción dedicado a noticias sobre las temporadas líricas en Lima no ha superado el 50\% por nota y hay 
una preferencia por la imagen al contenido, así como por la información a la opinión y el análisis. De la muestra escogida, hay textos con diversas imprecisiones que demostrarían un descuido de los editores de turno por corroborar información con otros medios o documentos. Asimismo, hay críticas que omiten ciertos aspectos de la función como se ha detallado en párrafos anteriores.

\section{Recomendaciones finales}

A lo largo del presente trabajo se ha detallado la importancia de la preparación del periodista que desee dedicar su carrera al campo cultural. Además, se puede colegir que la difusión de cultura a través de medios masivos, como un periódico, requiere, al igual que el conocimiento, la capacidad de quien escribe para poder hacer accesible la información a todo tipo de público.

Los medios de comunicación deberían proponer una serie de contenidos que serán consumidos por el público. Para lograrlo, es necesario que cuenten con especialistas tanto en las áreas de redacción y edición que dediquen su tiempo a investigar y conocer más sobre cultura y manifestaciones artísticas.

Asimismo, las universidades en el Perú deben insertar en sus planes de estudio la cultura y el arte como especialización en la carrera de periodismo. Y es que la falta de preparación, la poca difusión y el alto grado de superficialidad de las informaciones que usualmente se presentan hace pensar que el periodismo cultural es una especialidad light. No obstante, es responsabilidad del comunicador construir su credibilidad y respetar a su profesión y al público ofreciendo contenidos de calidad.

\section{Fuentes consultadas}

Asociación Prolírica (2012). "La lírica en el Perú". Extraída el 20/VI/2012 desde desde http://www.asociacionromanza.org/index.php?option=com_content\&view $=$ article\&id $=88$ \&Itemid $=68$

Bedoya, R. (2010, abril 27). “La música sentimental”. El Comercio, sección “Luces”, p. 4.

Contreras, D. (2005). “El lenguaje periodístico. Características y limitaciones”. Extraída el 3/XI/2013 desde http://www.perspectivesoncommunication.com/files/3PoCoct05es.pdf

Gargurevich, J. (2009, julio 12). "Nuevas definiciones para el periodismo” Extraída el 10/ $\mathrm{XI} / 2013$ desde http://www.abe.cl/invitado-Gargurevich29.html

Guédez, V. (2002). "La cultura y la educación: ¿factores de capital social o de capital ideológico?”. Extraída el 10/XI/2013 desde http://apps.ucab.edu.ve/clubderomaVenezuela/ arch_nac/cultura.pdf 
Kliksberg, B. (1999). “Capital Social y cultura, claves esenciales del desarrollo”. Revista de la CEPAL, núm. 69, pp. 85-102. Extraída el 6/XI/2013 desde http://www.eclac.cl/ publicaciones/ SecretariaEjecutiva/7/lcg2067/kliksbergesp.pdf

Martín-Barbero, J.; Ulanovsky, D. y Garavito, F. (eds.) Periodismo y cultura. Bogotá: Tercer Mundo Editores.

Martín Serrano, M. (1984). "Las funciones sociales que cumplen los medios de comunicación de masas". Anàlisi, num. 9, pp. 199-208. Extraída el 11/XI/2013 desde http:/ddd.uab.es/pub/analisi/02112175n9p199.pdf

Molinari, M. (2013, octubre 4). Director ejecutivo de "Sinfonía por el Perú". Entrevista personal. Lima. Extraída el 11/II/2014 desde http://camelloparlante.com/2013/11/20/ miguel-molinari-nuestros-cantantes-de-opera-son-los-que-han-puesto-el-nombre-delperu-en-alto/

Núñez Grassals, R. (2011, mayo 30). "La ética como base del ejercicio del periodismo". Extraído el 3/XI/2013 desde http://redciberetica.org/inicio/167-la-etica-como-base-delejercicio-del-periodismo

Planas, E. (2010, enero 5). "Un canto a la independencia". El Comercio, sección "Luces", p. C3.

Quezada Macchiavello, J.

_(2009, abril 27). "Un elenco de clase mundial”. El Comercio, sección "Luces", p. 8.

_(2008, abril 2). “Ópera grande en el Callao de Granda". El Comercio, sección "Luces”, p. 8.

Rivas Iturralde, V. (2010, junio 4). “¿Es posible la crítica de ópera? Primera parte”. Extraída el 30/X/2013 desde http://www.proopera.org.mx/pasadas/julagos2/revista/54 ensayo_julio.pdf

RPP Noticias (2009, junio 8). "La Traviata y Elixir de Amor nuevas propuestas de ópera". Extraída el 17/II/2014 desde http://www.rpp.com.pe/detalle.php?nid=186841

Sánchez, M. (2013, mayo 31). “Existe periodismo cultural en el Perú?”. Extraída el 11/ II/2014 desde http://puntoedu.pucp.edu.pe/noticias/existe-periodismo-cultural-en-el-peru/

Servat, A. (2009, abril 18). “Attila”. El Comercio, sección “Luces”, p. 4.

Trivelli C.

_(2011a, febrero 24). “Tras los pasos de Juan Diego”. El Comercio, sección “Luces”, p. 1.

_(2011b, febrero 24). “Andanzas de un tenor en Bogotá". El Comercio, sección "Luces”, p. 2. UNESCO (1982). "Declaración de México sobre las políticas culturales". Extraída el 3 / XI / 2013 desde http://portal.unesco.org/culture/es/files/35197/11919413801mexico_sp.pdf/ mexico_sp.pdf 


\section{Yáñez, L.}

_(2012, mayo 24). "Se nos vende por cultura cosas más relacionadas con el espectáculo y el mercado”. Extraída el 10/XI/2013 desde http://puntoedu.pucp.edu.pe/videos/entrevistagumersindo-lafuente-periodismo-cultural/

_(2005) "La crítica de arte como género periodístico: un texto argumentativo que cumple una función cultural". Razón y Palabra, núm. 45. Extraído el 4/XI/2013 desde http://www. razonypalabra.org.mx/anteriores/n45/ryanes.html 